\title{
Comparison Of The Efficacy Of Low Volumes Of Local Anesthetics Used In The Interscalene Brachialplexus Block With Tramadol Analgesia For Postoperative Analgesia In Shoulder Surgery
}

\section{Omuz Cerrahisinde Postoperatif Analjezi Amaçlı Ultrason Eşliğinde Uygulanan İnterskalen Brakial Pleksus Bloğunda Düşük Volümlerde Kullanılan Lokal Anestezik Etkinliğinin Tramadol Analjezisi İle Karşılaştırılması}

\author{
Güldeniz Argun ${ }^{1}$, Göze Çayırlı Demir ${ }^{2}$, Süheyla Ünver ${ }^{1}$ \\ ${ }^{1}$ SBÜ, Dr A Y Ankara Onkoloji Eğitim Araştırma Hastanesi, Anesteziyoloji ve Reanimasyon Bölümü, Ankara, \\ Türkiye \\ ${ }^{2}$ Kırıkkale Yüksek İhtisas Hastanesi, Anesteziyoloji ve Reanimasyon Bölümü, Kırıkkale, Türkiye
}

Dergiye Ulaşma Tarihi: 05.09.2018 Dergiye Kabul Tarihi: 16.10.2018 Doi: 10.5505/aot.2018.75537

\section{ÖZET}

GİRIŞ ve AMAÇ: Bu çalışmada, omuz cerrahisi uygulanmış vakalarda ultrasonografi yardımıyla gerçekleştirilen interskalen brakial pleksus bloğunda, 2 farklı düşük volümde lokal anestezik kullanımının postoperatif analjezi üzerine etkilerinin, intravenöz tramadol analjezisiyle karşılaştırılması amaçland. YÖNTEM ve GEREÇLER: Hastanemiz Etik Kurul onayı (2013-4/52) alınarak, ASA I-III, 18-80 yaş arası omuz cerrahisi uygulanacak 69 hasta çalışmaya alındı ve rastgele 3 gruba ayrıldı: Grup I; $3 \mathrm{ml} \% 0.5$ bupivakain, $2 \mathrm{ml}$ prilokain toplam $5 \mathrm{ml}$, Grup II: $3 \mathrm{ml} \% 0.5$ bupivakain, $2 \mathrm{ml}$ prilokain ile $5 \mathrm{ml}$ salin toplam $10 \mathrm{ml}$., Grup III 2 $\mathrm{mg} / \mathrm{kg}$ tramadol intravenöz aldı. İnterskalen sinir bloğu, genel anestezi altında ultrasonografi ve periferik sinir stimülatörü yardımıyla uygulandı. Blok başlama ve derlenme zamanları, grupların ağrı skorları, ilk analjezik gereksinim zamanları ve tüketilen total analjezik miktarları gruplar arasında karşılaştırıldı. BULGULAR: Sensoryal ve motor blok başlama zamanı, yüksek volüm kullanılan grupta (Grup II) daha kısaydı (sensoryal; 5.54/8.54 dakika, motor; 8.30/11.00 dakika). Sensoryal ve motor blok sonlanma süreleri, yüksek volüm kullanılan grupta anlamlı olarak uzundu. (Grup I/ Grup II: 399.50/288.00 ve 424.00/330.50 dakika). İlk analjezik gereksinim zamanı intravenöz analjezi grubunda diğer gruplara göre anlamlı olarak daha kısaydı. (Grup I; 6.86 \pm 0.40 , Grup II; $7.06 \pm 0.52$, Grup III;3.25 \pm 0.40 saat, $\mathrm{p}<0,05)$. Total analjezik tüketimi de Grup III'de anlamlı yüksekti. Tüm değerlendirme zamanlarında ağrı skoru ortalamaları, blok yapılan gruplarda, intravenöz tedavi grubuna göre anlamlı olarak düşüktü.

TARTIŞMA ve SONUÇ: Düşük volümlü lokal anestezikle uygulanan interskalen sinir bloğu, yüksek volümle uygulanan blok ile benzer şekilde, intravenöz analjezi grubuna göre ağrı skorları, ek analjezik gereksinim zamanı ve total analjezik tüketimi bakımından üstün bulunmuştur. Düşük volümle ultrasonografi eşliğinde yapılan interskalen sinir bloğu ile yeterli blok başarısının elde edilebileceğini ve tüketilen analjezik miktarının azalabileceğini

düşünüyoruz.

Anahtar Kelimeler: Ortopedi, omuz cerrahisi, postoperatif ağrı, ultrason, interskalen brakial pleksus bloğu, lokal anestezik.

\footnotetext{
ABSTRACT

INTRODUCTION: The aim of this study was to compare the postoperative analgesic effects of 2 different low volumes of local anesthetics used in interscalene nerve block with intravenous tramadol analgesia in patients underwent shoulder surgery.

METHODS: After approval of Hospital Ethics Committee (2013-4/52), 69 patients who were ASA I-III, 18-80 years old and scheduled for shoulder surgery were included in the study and randomly divided into 3 groups: Group I received $3 \mathrm{ml} 0.5 \%$ bupivacaine, $2 \mathrm{ml}$ prilocaine, total is $5 \mathrm{ml}$, Group II: $3 \mathrm{ml} 0.5 \%$ bupivacaine, $2 \mathrm{ml}$ prilocaine and $5 \mathrm{ml}$ saline total is $10 \mathrm{ml}$ and Group III $2 \mathrm{mg} / \mathrm{kg}$ tramadol intravenously. The interscalene nerve block was applied under general anesthesia using USG and peripheral nerve stimulator. Onset of block and recovery times, pain scores of the groups, first analgesic requirement times and total amount of analgesic consumed were compared between the groups.
} 
RESULTS: The time for sensory and motor block onset were shorter in the high-volume group (Group II) (Sensory; 5.54 / 8.54, motor; $8.30 / 11.00 \mathrm{~min}$ ). Sensory and motor block termination times were significantly longer in Group II (GroupI / GroupII: 399.50/288.00, 424.00/330.50 minutes). The first analgesic requirement times were significantly shorter in the intravenous tramadol group (Group I; 6.86 \pm 0.40 , Grup II; 7.06 \pm 0.52 , GrupIII;3.25 \pm 0.40 hour, $\mathrm{p}<0,05$ ). Total analgesic consumption was also significantly higher in Group III. The mean pain scores were significantly lower in the block groups than the intravenous treatment group at all assessment times.

DISCUSSION AND CONCLUSION: Interscalene nerve block applied with low volume local anesthetics was found to be superior to intravenous analgesia group, similar to high volume, in terms of pain scores, additional analgesic requirement time, and total analgesic consumption. We think that adequate block success can be achieved in the interscalene nerve block performed with ultrasonography using low volume and the amount of analgesic consumption can be reduced.

Keywords: Orthopedics, shoulder surgery, postoperative pain, ultrasound, interscalene brachial plexus block, local anesthetic.

\section{GíRIŞ}

Periferik sinir blokları tek başına ya da genel anesteziyle birlikte anestezi yöntemi olarak yaygın olarak kullanılmaktadır $(1,2)$. Postoperatif ağrı tedavisi için kullanımı gün geçtikçe yaygınlaşmaktadır. Postoperatif ağrı, hastaların erken taburcu edilmelerini engelleyen, dolayısıyla maliyet artışına neden olan önemli bir etkendir $(1,3)$. Periferik sinir bloklarında ultrason kullanımı, bloklarda başarı oranını büyük ölçüde arttırmaktadır $(4,5)$. Sinirlerin görülerek blok uygulanması, daha düşük volüm lokal anestezik kullanılarak başarılı blok elde edilmesini sağlamakta ve intravenöz ilaç tedavisinin neden olabileceği komplikasyon oranını düşürmektedir (6). İntravenöz ilaç tedavisiyle periferik sinir bloklarının postoperatif analjezi üzerine etkisinin karşılaştırıldığı çalışmalar, periferik sinir bloklarının, postoperatif analjezik etkinliğinin daha uzun olduğunu göstermektedir $(7,8)$. Omuz cerrahisi postoperatif dönemde ağr1 kontrolünde etkin tedaviye ihtiyaç duyulan cerrahilerdendir.

$\mathrm{Bu}$ çalışmada, omuz cerrahisi uygulanmış vakalarda ultrasonografi yardımıyla gerçekleştirilen interskalen brakial pleksus bloğunda, konvansiyonele göre düşük iki farklı volümde lokal anestezik kullanımının postoperatif analjezi üzerine etkileri intravenöz tramadol analjezisiyle karşılaş̧ırıldı.

\section{MATERYAL ve METOD}

Hastanemiz Etik Kurul onay1 (2013-4/52) alınarak, ASA I-III, 18-80 yaş arası omuz ve humerus üst ucutümör rezeksiyon cerrahisi uygulanacak 69 hasta, onamları alınarak çalışmaya dahil edildi. Lokal anestezik allerjisi, ileri respiratuar veya kardiyak hastalık, diğer tarafta diyafragma paralizisi, pnömonektomi, diyabet nöropatisi, periferik nöropati, nöromüsküler hastalık, koagulopati, blok uygulanacak alanda enfeksiyon, yara skar1 mevcudiyeti, çalışma kapsamına alınmama kriterlerini oluşturdu.

Bütün hastalara propofol $2 \mathrm{mg} / \mathrm{kg}$, fentanil 1-2 $\mu \mathrm{g} / \mathrm{kg}$ ve rokuronyum $0.5 \mathrm{mg} / \mathrm{kg}$ ile anestezi indüksiyonu sağland1.50\% oksijen, $50 \% \mathrm{~N} 2 \mathrm{O}$ ve 2 MAC sevofluran ile anestezi idamesi yapıldı. Çalışmaya alınacak hastalar, kapalı zarf seçme yöntemiyle randomize olarak 3 gruba ayrıldı. Ekstübasyondan önce Grup I hastalara; $3 \mathrm{ml} \% 0.5$ bupivakain, $2 \mathrm{ml}$ prilokain toplam 5 $\mathrm{ml}$ ile interskalen blok, Grup II hastalara: $3 \mathrm{ml}$ $\% 0.5$ bupivakain, $2 \mathrm{ml}$ prilokain ile $5 \mathrm{ml}$ salin toplam $10 \mathrm{ml}$ ile interskalen blok ve Grup III hastalara $2 \mathrm{mg} / \mathrm{kg}$ tramadol IV uyguland. Blok uygulanacak hastalara (Grup I, Grup II) ekstübasyondan hemen önce ultrasonografi ve periferik sinir stimülatörü yardımıyla interskalen blok uygulandi. Uygulamada hasta yüzü karşı tarafa doğru çevrildi. Blok uygulanacak boyun bölgesi antisepsisi sağlandıktan sonra, yüksek frekanslı lineer ultrasonografi (Esaote, My LabFive) probu yerleştirildi. Boyun orta hattından itibaren trakea, juguler ven, karotid arter ve lateralinde interskalen sinirler görüntülendi. 22 gauge 50 mm yalıtılmış ve ucu akımı ileten iğne (Stimuplex D.B. Braun Medical) ile $1.5 \mathrm{~mA}$ akımda, $1 \mathrm{~Hz}$ frekans ve $0.1 \mathrm{~ms}$ hizda ayarlanan periferik sinir stimülatörü (Stimuplex HNS11, B Braun Medical) ile ultrasonda görüntülenen interskalen sinirlere akım uygulandı. En güçlü motor cevaplar omuz ve kolda görüldükten sonra, akım şiddeti önce $1 \mathrm{~mA}$ e daha sonra 0.5 $\mathrm{mA}^{\prime}$ e düşürülerek en düşük akımda motor cevap elde edildikten sonra, aspirasyonda kan 
gelmediği gözlendiğinde lokal anestezik ilaç sinirlerin etrafina enjekte edilerek ultrasonografi ile ilacın dağılımı izlendi. Hastalar ekstübe edildikten sonra sensoryal blok, servikal 4-torakal 1dermatomlarında pinpirik testiyle ve motor blok Modifiye Bromage Skalası'yla değerlendirildi (Modifiye Bromage Skalası, $0=$ motor blok yok, $1=$ omuz abdüksiyonu yok, 2=hem omuz abdüksiyonu, hem dirsek fleksiyonu yok, $3=$ tam motor blok). Birinci derece blok oluşmas1, motor blok başlama zamanı olarak kabul edildi. Duyu ve motor blok başlama zamanları, derlenme zamanları, grupların 1., 6. ve 24. saatlerdeki ağr1 şiddetleri (Vizüel Analog Skala, VAS, 0 = ağr1 yok, $10=$ en şiddetli ağrı tanımlayacak şekilde ağrılarına 0-10 arasında puan vermeleri istendi), ilk analjezik gereksinim zamanlarıve 24 saatte tüketilen analjezik miktarı (tramadol, $\mathrm{mg} / \mathrm{kg}$ ) kaydedildi. VAS değerleri 3 ve üzerinde ise 1 $\mathrm{mg} / \mathrm{kg}$ tramadolek analjezik olarak uyguland 1 .

\section{Istatiksel analiz}

Araştırmanın güç analizi yapılırken VAS değerleri primer amaç olarak kullanıld1; her grupta 21 hasta olacak şekilde toplam 63 hasta, alfa hatas 0.05 , beta hatasi 0.20 ve etki boyutu $0.5^{\prime}$ le $\% 90$ test gücü sağlamaktaydı. Veri kayb1 olacağ1 düşünülerek her grupta 23 hasta olacak şekilde 69 hasta çalışmaya dahil edildi. İstatistik analiz için The Statistical Package for the Social Science (SPSS Inc, Chicago, Illinois, USA) version 15.0 kullanıldı. Grupların normal dağılım gösterip göstermediği Shapiro-Wilk testi ile anlaşıldı. Parametrik test ön şartları sağlandığından, 3 grup ortalama farkları için Anova Testi, gruplar arasındaki VAS değerleri arasındaki bağlantıyı değerlendirmek için Pearson Korelasyon Testi kullanıldı.

Kruskal-Wallis ve Mann- Whitney U Testleri gruplar arası fark analizinde kullanıldı.

\section{BULGULAR}

Gruplar demografik verileri açısındanbirbirine benzerdi (Tablo 1). Sensoryal blok başlama zaman1, yüksek volüm lokal anestezik kullanılan grupta $(10 \mathrm{ml})$ düşük volüm $(5 \mathrm{ml})$ lokal anestezik kullanılan grubagöredaha kısaydı ve fark anlamlıydı (Grup I; $8.54 \pm 1.20$ dk.,Grup II; $5.54 \pm 1.10 \mathrm{dk}, \mathrm{p}<0.05$ ). Motor blok başlama zamanı Grup I' de anlamlı olarak daha uzundu. (Grup I'de 11.00土1.08 dk, Grup II'de
$8.30 \pm 1.05 \mathrm{dk}, \mathrm{p}<0.05)$. Grup II'de sensoryal ve motor blok sonlanma süreleriGrup I'e göre anlamlı olarak uzun bulundu. (Tablo 2, $\mathrm{p}<0.05$ ). İk analjezik gereksinim zamanları farklı volümlerde lokal anestezik kullanılan Grup I ve Grup II'de birbirinden farklı değilken, intravenöz ilaç tedavisi uygulanan Grup III'de anlamlı olarak kısaydı (Tablo 2,p<0.05). İlk 24 saatteki ortalama analjezik tüketimleri Grup I'de $0.34 \pm 0.1 \mathrm{mg} / \mathrm{kg}$, Grup II' de $0.43 \pm 0.12 \mathrm{mg} / \mathrm{kg}$ ve Grup III' de $1.34 \pm 0.7 \mathrm{mg} / \mathrm{kg}$ olarak bulundu ve Grup III'de, Grup I ve II'ye göre anlamlı olarak yüksekti $(\mathrm{p}<0.05)$.

Tablo 1: Grupların Demografik Özellikleri

\begin{tabular}{|l|l|l|l|}
\hline & $\begin{array}{c}\text { GRUP I } \\
(\mathbf{n = 2 3})\end{array}$ & $\begin{array}{c}\text { GRUP II } \\
(\mathbf{n = 2 3})\end{array}$ & $\begin{array}{c}\text { GRUP III } \\
(\mathbf{n = 2 3})\end{array}$ \\
\hline Yaş (Yıl) & $46 \pm 0.49$ & $49 \pm 0.54$ & $47 \pm 0.57$ \\
\hline $\begin{array}{l}\text { Ağırlık } \\
\text { (kg) }\end{array}$ & $78 \pm 1.02$ & $76 \pm 1.08$ & $80 \pm 1.50$ \\
\hline $\begin{array}{l}\text { Cinsiyet } \\
\text { (K/E) }\end{array}$ & $19 / 14$ & $18 / 15$ & $19 / 14$ \\
\hline $\begin{array}{l}\text { ASA } \\
\mathbf{1 / 2 / 3}\end{array}$ & $7 / 15 / 1$ & $9 / 11 / 3$ & $12 / 9 / 2$ \\
\hline
\end{tabular}

Veriler: Ortalama \pm Standart sapma (Ort \pm SD) ve $n$ (hasta sayıs1) olarak verilmiştir.

Grup I: $5 \mathrm{ml}$ volüm, Grup II: $10 \mathrm{ml}$ volüm, Grup III:

İntravenöz tramadol

VAS ortalamaları, blok yapılan gruplarda, intravenöz analjezik tedavisi uygulanan gruba göre tüm ölçüm zamanlarında anlamlı olarak düşüktü (Şekil 1, p<0.05) (Şekil1). Grup I ve Grup II'nin 1,6. ve 24. saat VAS ortalamaları arasinda ise anlamlı bir farklılık yoktu.

\section{TARTIŞMA}

İki ayrı volümdelokal anestezikle uygulanan interskalen brakial pleksus bloğunda, intravenöz tramadol grubuna göre daha etkin bir postoperatif analjezi elde edildi. Yüksek volümde lokal anestezik kullandığımız grupta blok başlangıcının daha hızlı, etki süresinin de daha uzun olduğunu gördük. Ancak hastaların ağrı skorları, iki blok grubunda birbirinden farklı değildi ve ilk analjezik gereksinim zamanları ile 24 saatteki total analjezik tüketimleri birbirine benzerdi.

Tablo 2: Sensoryal ve Motor Blok Özellikleri ve Analjezik Gereksinimleri (Ort $\pm \mathrm{SD})$ 


\begin{tabular}{|c|c|c|c|}
\hline & $\begin{array}{c}\text { GRUP I } \\
(n=23)\end{array}$ & $\begin{array}{c}\text { GRUPII } \\
(\mathbf{n}=23)\end{array}$ & $\begin{array}{c}\text { GRUP III } \\
(\mathbf{n}=\mathbf{2 3})\end{array}$ \\
\hline $\begin{array}{l}\text { Sensoryal blok } \\
\text { başlama süresi } \\
\text { (dk) }\end{array}$ & $8.54 \pm 1.20$ & $5.54 \pm 1.10^{*}$ & \\
\hline $\begin{array}{l}\text { Motor blok } \\
\text { başlama süresi } \\
\text { (dk) }\end{array}$ & $11.00 \pm 1.08$ & $8.30 \pm 1.05 *$ & \\
\hline $\begin{array}{l}\text { Sensoryal blok } \\
\text { derlenme süresi } \\
\text { (dk) }\end{array}$ & $288.00 \pm 5.20$ & $\begin{array}{c}399.50 \pm 10.02 \\
*\end{array}$ & \\
\hline $\begin{array}{l}\text { Motor blok } \\
\text { derlenme süresi } \\
\text { (dk) }\end{array}$ & $330.50 \pm 5.20$ & $424.00 \pm 6.70^{*}$ & \\
\hline $\begin{array}{l}\text { Illk analjezik } \\
\text { gereksinim } \\
\text { zamanı (sa) }\end{array}$ & $6.86 \pm 0.40$ & $7.06 \pm 0.52$ & $3.25 \pm 0.40^{*}$ \\
\hline $\begin{array}{l}24 \text { sa'de total } \\
\text { analjezik } \\
\text { tüketimi } \\
\text { (tramadol } \\
\mathrm{mg} / \mathrm{kg} \text { ) }\end{array}$ & $0.34 \pm 0.10$ & $0.43 \pm 0.12$ & $1.34 \pm 0.70 *$ \\
\hline
\end{tabular}

*: p<0.05, ml: Mililitre, IV: İntravenöz, sa: Saat, dk: Dakika

Wennerwirta ve arkadaşları üst ekstremite cerrahisi için genel anesteziyle interskalen pleksus bloğunu birlikte uygulamışlardır. Operasyon sirasinda anestezinin daha stabil seyrettiğini, daha az miktarda anestezik ilaçlara ihtiyaç duyulduğunu ve intraoperatif stress ile postoperatif analjezik tüketiminin daha az olduğunu göstermişlerdir. Postoperatifağrının önlenmesinde, preoperatif uygulanan periferik sinir bloklarının etkili olabileceği belirtmişlerdir (9). Çalışmamızda periferik sinir bloğu, anestezi sonlandırılmasından hemen önce, hasta spontan solunumdayken uygulanmıştır. Kas gevşetici etkisi en aza düşürülmüş, aynı zamanda uyanık hastanın blok uygulanma sırasında ağrı duyması engellenmiştir. Blok süresinin operasyondan sonra daha uzun sürmesi istendiğinden blok uygulamas1 operasyon sonunda yapılmıştır. Çalışmamızla benzer şekilde, interskalen sinir bloğunun operasyon sonunda uygulandığ 1 bir çalışmada, interskalen blok yapılan hastalarda postoperatif VAS skorlarının intravenöz analjezi uygulanan gruba göre daha düşük olduğu gösterilmiştir. Aynı çalışmada morfin tüketimi ve yan etki insidansıda daha düşük bulunmuştur (10).

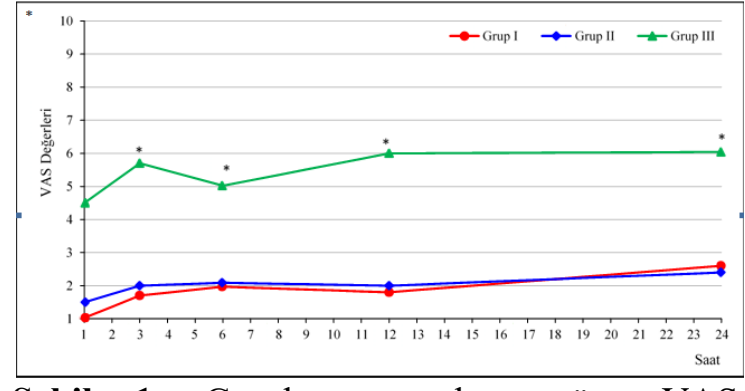

Şekil 1. Grupların saatlere göre VAS ortalamalar1

Ultrasonun perferik sinir bloklarında kullanılmaya başlanmasıyla, uygulanan lokal anestezik volümleri azalmış ve aynı başarıda bloklar elde edilmiştir. Morhofer ve arkadaşları, 4 ve 14.8 mililitre volümde $\% 1$ mepivakain ile ultrason eşliğinde uyguladıkları aksiller sinir bloğunda sensoryal blok başlama zamanını, düşük volüm grubunda daha uzun (25/15 dakika), derlenme süresini ise daha k1sa bulmuşlardır (125/152 dakika).Blok başarısını ise her iki grupta benzer bularak, ultrason eşliğinde düşük volüm lokal anestezik kullanılarak da başarılı blok elde edilebileceğini göstermişlerdir. Çalışmamızla uyumlu olarak, bu çalışmada da, periferik sinir bloğunun etkinliği, intravenöz analjezik tüketiminin azalmasıla ve hastaların analjezik kullanmadan daha uzun periyot geçirmeleriyle değerlendirilmiştir (11).

Oberndorfer ve arkadaşları ultrason ve nörostimülatör eşliğinde uyguladıkları femoral sinir bloğu çalışmalarında, ultrason kullanımı ile daha düşük lokal anestezik kullanılarak etkili blok oluşturulabileceğini göstermişlerdir (12). Literatürde 20,30, 40 mililitre gibi değişen volümde lokal anestezik kullanılarak uygulanan üst ekstremite sinir bloklarında, artan volümlerde, ilacın daha çok yayılmasına bağlı etki başlama süresinin kısaldığı görülmüştür (13). Çalışmamızda yüksek volüm olarak uyguladığımız $10 \mathrm{ml}$ lokal anestezik volümü bile üst ekstremite periferik sinir blokları için geleneksel olarak kullanılan volümlere göre düşük kalmaktadır. Düşük lokal anestezik volümü olarak kullandığımız $5 \mathrm{ml}$ lokal anestezikle de, intravenöz tramadol grubuna göre daha etkin bir postoperatif analjezi sağlanmıştır. Düşük volümde lokal anestezik uygulaması, hem maliyetin düşmesi açısından, hem de yüksek volümün dokulara yapacağ1 etkiden korunulması açısından önemlidir. 
Büttner ve arkadaşlarının çalışmalarında, omuz artroskopisinde genel anesteziyle kombine edilmiş interskalen sinir bloğunda $10 \mathrm{ml} 0.2 \%$ ropivakain kullanılmış ve intravenöz analjezik uygulanan grup ile postoperatif dönemde tüketilen analjezik miktarları karşılaştırılmıştır. On $\mathrm{ml}$ ropivakain ile başarılı blok elde edilmiş ve intraoperatif kullanılan propofol miktarı ve postoperatif dönemde kullanılan analjezik miktarı azalmıştır. Ayrıca postoperatif analjezi 2. güne kadar devam etmiştir (14).

Günübirlik inguinal herni operasyonlarında periferik sinir bloklariyla genel anestezinin birlikte kullanıldığ 1 bir başka çalışmada, periferik sinir bloğu eklenen grupta, kullanılan anestezik miktarlarının azaldığı, postoperatif analjezinin 2. güne kadar uzadığ 1 ve erken taburculuğun, intravenöz opioid tedavisi uygulanan gruba göre daha k1sa sürede sağlandığı izlenmiştir (15).Çalışmamızda 24. saat ağr1 değerlendirmesinde de, interskalen blok yaptı̆̆ımız grupların ağrı düzeyleri, intravenöz tramadol uygulanan gruba göre daha düşük bulunmuş ve postoperatif analjezinin 1.gündede devam ettiği görülmüştür.

\section{SONUÇ}

Periferik sinir bloklarının postoperatif ağrı tedavisindeki yeri tartışılmazdır. Günümüzde ultrason eşliğinde uygulanan periferik sinir bloklarında kullanılan ilaç volümü azalmıştır. $\mathrm{Bu}$ çalışmada, yüksek volüm lokal anestezikle daha çabuk başlayan ve etkisi daha uzun süren blok elde edilmiş olmakla beraber, ağrı skorları ve ek analjezik gereksinim zamanı değişmemiştir. Bu nedenle düşük volüm lokal anestezikle uygulanan periferik sinir bloklarında da aynı başarı oranının yakalanacağı ve intravenöz analjezi tedavisine gore daha etkin bir postoperatif analjezi sağlanabileceği sonucuna vardık.

Çıkar Çatışması: Yok

\section{REFERANSLAR}

1. White PF, Eng M. Fast-track anesthetic techniques for ambulatory surgery. Curr Opin Anaesthesiol. 2007;20:545-57.
2. Fosnot CD, Fleisher LA, Keogh J. Providing value in ambulatory anesthesia. Curr Opin Anaesthesiol. 2015;28:617-22.

3. Schug SA, Chong C. Pain management after ambulatory surgery. CurrOpin Anaesthesiol. 2009;22:738-43.

4. C.Aveline, H. Le Hetet, A. Le Roux, et al. Comparison between ultrasound-guided transversus abdominis plane and conventional ilioinguinal/iliohypogastric nerve blocks for day-case open inguinal hernia repair. British Journal of Anaesthesia.2011;106(3):380-6.

5. Eastburn E, Hernandez MA, Boretsky K. Technical success of the ultrasound-guided supra-inguinal fascia iliaca compartment block in older children and adolescents for hip arthroscopy.2017 Nov;27(11):1120-1124.

6. De José María $\mathrm{B}$, Banús E, Navarro-Egea M, et al. Tips and tricks to facilitate ultrasound-guided placement of periferal nerve catheters in children. Pediatric Anaesthesia. 2011; 21:974-979.

7. Barreveld A, Witte J, Chahal $\mathrm{H}$, et al. Preventive analgesia by local anesthetics: the reduction of postoperative pain by peripheral nerve blocks and intravenous drugs. Anesth Analg. 2013;116:114161.

8. Shin SW, Byeon GJ, Yoon JU,et al. Effective analgesia with ultrasoundguided interscalene brachial plexus block for postoperative pain control after arthroscopic rotator cuff repair.J Anesth. 2014;28(1):64-9.

9. Wennervirta J, Hynynen M, Koivusalo AM, et al. Surgical stress index as a measure of nociception/antinociception balance during general anesthesia. Acta Anaesthesiol Scand. 2008;52:103845.

10. Kaya M, Oğuz G, Şenel G, et al. Postoperative analgesia after modified radical mastectomy: the efficacy of interscalene brachian plexus block. J Anesth. 2013 Dec;27(6):862-7.

11. Marhofer $P$, Eichenberger $U$, Stöckli $S$, et al. Ultrasonographic guided axillary plexus blocks with low volumes of local anaesthetics: a crossover volunteer study. Anaesthesia. 2010;65:266-71.

12. Oberndorfer $U$, Marhofer $P$, Bösenberg $A$, et al. Ultrasonographic guidance siatic and femoral nevre blocks in children. Br J Anaesth. 2007; 98:797-801.

13. Rucci FS, Barbagli R, Pippa $P$, et al. The optimal dose of local anaesthetic in the Orthogonal Two-neddle Technique.Extend of Sensory Block After İnjection of 20,30 and $40 \mathrm{ml}$ of Anaesthetic Solution. Eur J Anaesthesiol.1997; 14:281-286.

14. Büttner $B$, et al. Combination of general anesthesia and peripheral nerve block with low dose ropivacaine reduces postoperative pain for several days after outpatient arthroscopy: A randomized controlled clinical trial. Medicine (Baltimore).2017; 96(6):6046.

15. Arora $S$, Chhabra A, Subramaniam R, et al. Transversus abdominis plane block for laparoscopic inguinal hernia repair: a randomized trial. J Clin Anesth. 2016 Sep;33:357-64. 